\title{
The Relationship between Positive Psychological Capital and Coping Styles: A Study on Young Adults
}

\author{
Pragati Gupta*, Nikita De, Subhalina Hati, Chayanika Saikia, Rita Karmakar $\left.{ }^{(}\right)$ \\ Amity University Kolkata, Kolkata, India \\ Email: *pragatiguptag9@gmail.com
}

How to cite this paper: Gupta, P., De, N., Hati, S., Saikia, C., \& Karmakar, R. (2019). The Relationship between Positive Psychological Capital and Coping Styles: A Study on Young Adults. Psychology, 10, 1649-1662. https://doi.org/10.4236/psych.2019.1012109

Received: April 1, 2019

Accepted: September 22, 2019

Published: September 25, 2019

Copyright (๑) 2019 by author(s) and Scientific Research Publishing Inc. This work is licensed under the Creative Commons Attribution International License (CC BY 4.0).

http://creativecommons.org/licenses/by/4.0/

Open Access

\begin{abstract}
The concept of psychological capital can be defined as an individual's positive psychological resource, which consists of four components which are self-efficacy/confidence, hope, optimism, and resilience. Positive Psychological Capital (PsyCap) is a recently developed higher order construct applied in the context of organizations, which has been hypothesized to aid employees cope with stress effectively in workplace increasing their psychological and physical well-being. Coping strategies refer to the specific efforts, both behavioural and psychological, that people employ to master, tolerate, reduce, or minimize stressful events by using rational, detached, emotional and avoidance coping. This study aims to explore the nature of Positive Psychological Capital (PsyCap) and Coping styles among male and female young adults and the relationship between PsyCap and Coping styles. Data were collected by using Psychological Capital Questionnaire (PCQ) \& Coping Styles Questionnaire (CSQ), administered on 100 participants aged between $18-25$ years, from different colleges of Kolkata, using stratified simple random sampling method. Results indicated the following: 1) Hope and Resilience are significantly higher among female young adults than their male counterparts. 2) Detached and Avoidance coping style are significantly higher among male young adults \& emotional coping style is significantly higher among female young adults. 3) Positive correlations exist between all the dimensions of PsyCap and functional coping style and negative relationship exists between dimensions of PsyCap and dysfunctional coping style. The study implies the effective use of PsyCap to promote positive outcomes, fostering development in young adult population.
\end{abstract}

\section{Keywords}

Coping Styles, Positive Psychological Capital (PsyCap), Young Adults 


\section{Introduction}

In today's competitive educational environment everyone is trying to achieve higher degrees of good professional roles and responsibilities. This is due to the high complexity and increased demand from academic world and society. Of late, young adults face challenges regarding their academic coursework, managing interpersonal relationships (family, friends, extended relatives etc) and romantic relationships, ambiguous roles and responsibilities, competitive examinations for pursuing higher degree, excessive assignments, to attain higher grades, financial problems in the family, lack of time management etc. overall which can negatively affect their psychological and physical well-being. For young adults it is a crucial time period for career development. So there is a need to understand the coping styles (adaptive/maladaptive) they use while facing the stressor, and how much mental strength they have and positive psychological resources to deal with it.

\subsection{Positive Psychological Capital (PsycCap)}

Psychological Capital (PsyCap) was proposed by Luthans \& his collegues (2004), drawn from Positive and Organizational Psychology. The concept of psychological capital was originally designed for organizations and is considered as an important subset of human capital.

Psychological capital (PsyCap) draws from the significant body of research that Seligman and Csikszentmihalyi (2000) have initiated in the wake of positive psychology movement i.e. which switched the focus of study from human deficits like mental illness to human assets like resilience, optimism etc. which would allow individuals, groups or even organizations to thrive and prosper. According to Luthans (2002), there are some psychological constructs (self-efficacy, hope, optimism and resilience) which meet the criteria of being positive, based on the theory and research, and state-like open to development, change and management for performance improvement. These four constructs along with happiness were labelled as positive organizational behavior (POB). Luthans and Youssef bundled four of these states into the higher-order construct "Positive Psychological Capital" (Luthans \& Youssef, 2004). This composite construct has been defined as "an individual's positive psychological state of development and is characterized by: 1) having confidence (self-efficacy) to take on and put in the necessary effort to succeed at challenging tasks determines how we feel, think and motivate ourselves; 2) making a positive attribution (optimism) about succeeding now and in the future; 3 ) persevering toward goals and, when necessary, redirecting paths to goals (hope) in order to succeed and; 4) when beset by problems and adversity, sustaining and bouncing back and even beyond (resilience) to attain success". PsyCap represents one's positive appraisal of circumstances and probability for success based on motivated efforts and perseverance (Luthans \& Youssef, 2007b). Psychological capital (PsyCap), is a meta-concept that incorporates various traits that have been found to foster psychological resi- 
lience (Roddenberry \& Renk, 2010).

PsyCap is shown to be associated with desirable employee attitudes, such as staying intentions (Avey et al., 2011), job satisfaction and commitment (Larson \& Luthans, 2006). Employees high in PsyCap are found to be more empowered, which generally leads to less turnover intentions (Avey et al., 2008) and the reduction of absenteeism (Avey et al., 2006). PsyCap is shown to be developable through training interventions, which makes it a useful and tangible construct which is actually able to influence individuals and the whole organizations in a positive way (Luthans et al., 2008). Various studies have suggested that PsyCap helps in improving psychological and physical well-being, by reducing the stress (Baron et al., 2013).

Psychological Capital helps to trigger cognitive, affective, conative and social mechanisms, leading to psychological well-being (Avey et al., 2010; Newman et al., 2014), and can facilitate the interpretation and memory retention process for specific experiences and satisfaction to have greater impact on psychological well-being (Diener \& Biswas-Diener, 2008).

A study by Riolli et al. (2012) suggested that persons high in PsyCap will readily withstand stress and maintain physical and psychological well-being and happiness in the face of academic stress.

Individuals who believe that they can do something about their stress have a more positive psychological adaptation relative to those who do not hold such beliefs (Roddenberry \& Renk, 2010).

\subsection{Coping Styles}

Stress is a complex reaction that affects our cognition, behaviour, emotions and physiology. Stress arises not from the demands people face, but from people's perceived inability to deal with those demands to their own satisfaction (Hiebert, 1983; Lazarus \& Folkman, 1984). Hiebert (1983) maintains that stress control is best approached by developing a wide range of coping skills, some aimed at dealing with the demands people face (stressor management strategies) and others aimed at helping people calm their stressful reactions (stress management strategies). Both stressor management strategies and stress management strategies are necessary for people to cope with the demands placed upon them (Hiebert, 2002). Successful coping requires a set of skills and knowledge that are adequate for dealing with a variety of situations (Hiebert, 2002). Lazarus and Folkman (1984) define coping as the "changing thoughts and acts an individual uses to manage the external and or internal demands of a specific person environment transaction that is appraised as stressful". Coping strategies are seen to operate by manipulating one's physical, psychological and behavioural responses to stressful events (Weinstein et al., 2009). Two general coping strategies have been distinguished: problem-focused strategies are efforts to do something active to alleviate stressful circumstances, whereas emotion-focused coping strategies involve efforts to regulate the emotional consequences of stressful or potentially stressful events (Folkman \& Lazarus, 1980). 
According to Roger et al. (1993), coping has been distinguished into four distinct styles. Roger et al. (1993) \& Elklit (1996) found four clusters of items for Coping Styles Questionnaire (CSQ). These items represent Rational, Detached, Avoidant, and Emotional Coping Style.

Rational coping style includes action-based, problem solving strategies and is considered an adaptive style. A Detached coping style includes strategies and beliefs that create cognitive distance and independence between oneself and a stressor (Elklit, 1996). Strategies aimed at manipulating and distorting the way one feels about an event or situation are classified as Emotional coping style (Roger et al., 1993), Avoidant or escape coping, is a maladaptive coping mechanism characterized by the effort to avoid dealing with a stressor. Logical/ Rational coping is a problem-focused strategy and Detached coping is an approach based on which the individual gets far away from the problem to face it and reduce the potential influence of emotion. Rational and detached coping are generally regarded as an efficient coping style and emotional and avoidant coping as an ineffective coping style (Roger et al., 1993). Both avoidant and emotional coping are considered maladaptive (Elklit, 1996).

Positive coping strategies successfully diminish the amount of stress being experienced and provided constructive feedback for the user, which is functional and productive. Negative coping strategies might be successful at managing or abating stress, but the result is dysfunctional \& non-productive. Coping strategies change and mature across the lifespan owing to changes in cognitive, social and behavioural skills and the emergence of different stressors (Frydenberg, 1997).

\section{Literature Review}

Psychological Capital (PsyCap) (Luthans \& Youssef, 2007b) encompassing Hope, Efficacy, Resilience, \& Optimism has been an emerging, empirically tested, effective and validated construct in the fields of Business and Management. But in the last decade PsyCap has begun to be applied in other settings including academic field, among mental health workers, in sports etc.

A research study by Yan \& Zhang (2016), through empirical analysis found out that PsyCap of college graduates is in good condition as a whole \& adopts positive coping. The positive coping of college \& graduate students has a significant positive impact on the PsyCap, while the negative coping has a significant negative impact on the PsyCap. It has a positive impact on interpersonal relationships of college student.

Researches among college students illustrate evidence of strong association between mental health \& self confidence in addition to socially supportive climate, smooth transitioning into college and a deep sense of belonging (Fink, 2014).

Female adolescents were shown to use maladaptive coping styles more frequently than male adolescents (Hampel \& Petermann, 2005; Al-Bahrani et al., 2013). 
Laschinger \& Grau (2012) identified that increased psychological capital was negatively related to emotional exhaustion, burnout and increased physical and mental well-being among nurses.

A research study by Riolli et al. (2012) revealed that students who maintain higher PsyCap will perceive the academic environment as being less distressing and more than likely to see the positive elements (hope, resilience, efficacy and optimism) that contribute to their overall well-being.

A study by Luthans et al. (2007a), suggested that employees who are efficacious are more satisfied with their jobs due to better performance.

Dunkley et al. (2003) reported that the absence of active coping, as well as the recourse to emotional coping and distraction, increases the somatic symptoms among students.

Lazarus (2003) identified that human adaptability and coping strategy become enhanced with the help of different dimensions of psychological capital such as self-efficacy, optimism, hope and resilience.

From the above research findings it can be observed that people high in PsyCap can effectively deal with stress, using effective coping strategies. To the best of researcher's knowledge there are very few or almost no research regarding the relationship between Positive Psychological Capital and Coping Styles namely Rational, Detached, Avoidance, and Emotional among young adults. Therefore this study aims to investigate the relationship between Positive Psychological Capital and Coping Styles among young adults.

\section{Objectives of the Study}

The objectives of the study are as follows:

- To explore the nature of positive psychological capital (Hope, Self-efficacy, Resilience and Optimism) among male and female young adults.

- To ascertain the nature of coping styles (Detached, Rational, Emotional and Avoidance) adopted by male and female young adults.

- To find out the relationship between Positive Psychological Capital (Hope, Self-Efficacy, Resilience and Optimism) and Coping styles (Detached, Rational, Emotional and Avoidance) of young adults.

\section{Method}

\subsection{Participants}

100 participants aged between (18 - 25) years were selected from different colleges of Kolkata, WestBengal. A stratified random sampling method was used to collect the data. The participants are from different departments (Engineering, Mass Communication, B.Com, Political Science, Chemistry, Masters of Business Administration (MBA), Law, Bachelors of Business Administration (BBA) etc, from both Undergraduate and Post Graduate courses, including 45 Males \& 55 Females. Average age of the participants is 20.7 years with a Standard Deviation (S.D) of 1.58. Informed Consent was taken from the participant for collecting 
the data. The inclusion criterion is the college going student within the age range from (18 - 25), gender (both male and female), Familiarity with the English Language. Questionnaire was administrated face to face. Basic debriefing of the study was done (instructions regarding the demographic details, questionnaires was explained), confidentiality was ensured to every participant.

\subsection{Measures Used}

Demographic Information Schedule: It gathered Personal Information of the respondents such as gender, age, educational Status and parental education). Demographic Information Schedule helps in understanding about the participant characteristics, which is required for the basis for comparison/contrasts in the study, and how does it have an impact on dependent variable. It helps in the process of generalizations, by matching if representative sample is in close relationship with the target population. It helps us to build rapport with the participant, by knowing the basic information of the participant which will help in better interpersonal communication. It helps us to be better informed about the sample characteristics (individual differences affecting the results of the study).

Psychological Capital Questionnaire (PCQ): Psychological capital Questionnaire was developed by Luthans, Youssef, \& Avolio (2007c). It consists of 24-items to measure the Psychological Capital (PsyCap) construct. The PCQ is designed to assess the four components of PsyCap: hope, self-efficacy, optimism, and resilience, with each component assessed by six items. A sample item for assessing the hope facet is "I can think of many ways to reach my current goals". A sample efficacy item is "I feel confident in representing my work area in meetings with management". Optimism is measured with items such as "I'm optimistic about what will happen to me in the future as it pertains to work" and a sample resilience item is "I can get through difficult times at work because I've experienced difficulty before". Due to the nature of the participants in the study, the items on the PCQ were modified slightly to be more relevant. For example, I approach pilot training as if "every cloud has a silver lining", was replaced by I approach academic training/learning as "different ways of exploration about various topics". Responses were reported via a 6-point Likert-type scale ( 1 = "Strongly Disagree" to 6 = "Strongly Agree"). All the 24 items maintain a consistent positive direction of responses, three items $(13,20$, and 23 were reverse coded-which were in negative direction). The score for each dimension varies from 6 - 42. The higher score on each dimension indicates high on the respective dimensions. Responses were summed over all items into one overall PCQ score. The Cronbach's alpha of four dimensions was found to be 0.75 to 0.83 .

Coping Styles Questionnaire (CSQ): The CSQ (Rogers et al., 1993) is a 60 item scale that measures coping styles in four factors: Rational Coping (RATCOP), Detached Coping (DETCOP), Emotional Coping (EMCOP), and Avoidance Coping (AVCOP). It describes how we typically react to stress by circling "Al- 
ways (A)", "Often (O)", "Sometimes (S)", "Never (N)" for each item (where Always is 3 , Often is 2 , Sometimes is $1 \&$ Never is 0 ).

RATCOP is a 16 item scale that assess active problem solving type of coping (Example: "Try to find out more information to help make decision about things"). DETCOP is a 15 item scale that assess participant's detached coping style, i.e. viewing the problem in a realistic light and not identifying the problem (Example: "Feel independent of circumstances"). EMCOP is a 16 item scale that denotes an emotion oriented style of coping, focus on the negative emotions associated with the problem \& one's helplessness to solve the problem (Example: "Feeling worthless \& unimportant", \& "Feel overpowered and at the mercy of the situation"). AVCOP is a 13 item scale that deals with the avoidant coping behaviour, pretending that the problem doesn't exist \& ignoring it (Example: "Daydream about times in the past when things were better").

High scores on RATCOP \& DETCOP are conceptualized as an adaptive coping style (Roger et al., 1993). According to Rogers et al. (1993), High scores on EMCOP and AVCOP are conceptualized as maladaptive. Higher scores on each sub scales reflect higher levels of each coping style. The Cronbach's alpha of four dimensions range from 0.70 to 0.79

\section{Procedure}

The study is based on primary data. Data were collected from various college students in Kolkata, West Bengal, by random selection of the students both graduate and undergraduate of various disciplines. Rapport was established. After giving proper instructions, data were collected by administering above mentioned questionnaire. Participation was voluntary and anonymous. Significance of the study was explained after the participants filled their questionnaire.

\section{Results and Discussions}

The obtained data were analysed with the help of descriptive statistics (mean and standard deviation) and inferential statistics (t-test). In order to test the first objective, the means and standard deviations (SDs) and t-values of different dimensions of positive psychological capital (hope, resilience, efficacy and optimism) by gender were calculated and presented in Table 1.

Table 1. Mean, SD \& t values of different dimensions of Positive PsyCap by gender.

\begin{tabular}{cccccccc}
\hline $\begin{array}{c}\text { Dimensions of } \\
\begin{array}{c}\text { Positive Psychological } \\
\text { Capital }\end{array}\end{array}$ & \multicolumn{2}{c}{ Male } & \multicolumn{2}{c}{ Female } & t-value & Level of Significance \\
\cline { 2 - 5 } Hope & 25.33 & 3.411 & 28.22 & 4.31 & $\mathrm{t}_{(98)}=3.6$ & Significant at 0.01 level \\
Self-Efficacy & 25.71 & 3.91 & 26.76 & 4.74 & $\mathrm{t}_{(98)}=1.19$ & Not significant \\
Resilience & 25.71 & 3.98 & 27.83 & 4.78 & $\left.\mathrm{t}_{(98}\right)=2.38$ & Significant at 0.05 level \\
Optimism & 25.75 & 4.63 & 26.56 & 5.06 & $\left.\mathrm{t}_{(98}\right)=0.82$ & Not significant \\
\hline
\end{tabular}


Table 1 suggests that the female young adults are significantly higher on hope and resilience than their male counterparts. Mean for dimension of hope in females is 28.33 and SD is 4.31 , which is significantly higher than males with a mean of 25.33 and SD is 3.41, on the other hand females have significantly higher mean (27.83) and SD (4.78) for the PsyCap dimension resilience than male young adults which is mean (25.71) and SD (3.98). This implies that now-a-days women are becoming proactive, focusing on finding solutions, resistant to stress and possess positive attitude in life. Currently, females are provided more training to build up confidence and ability to fight back in adversity. No gender based difference was found in the other PsyCap dimensions (Self-Efficacy and Optimism).

In order to examine the second objective, the means and standard deviations (SDs) and t-values of different dimensions of coping styles (rational, detached, avoidance and emotional) by gender were calculated and presented in Table 2.

Table 2 reveals that the male young adults are significantly higher on detached and avoidance coping style than female counterpart. In case of detached coping style mean and SD for males is 25.4 and 6.106 respectively, which is significantly higher than mean and SD (21.6 and 6.014 respectively) for females, and also in the case of avoidance coping style, Mean and SD $(21.37,6.038)$ for males is higher than mean and SD $(18.85,5.43)$ for females. This finding is supported by the findings of Lawrence et al. (2006) which reported that males exhibit greater ability to detach themselves from the emotions of a situation and are more inclined to demonstrate bottling of emotions. The possible interpretation can be the role of sex differences and socialization process, men are not supposed to share problems, and keep it to themselves, as they are considered to be action oriented, direct and engage in problem focused coping. Males can create cognitive distance between themselves and the stressor but with continuous action-oriented strategies when the stressor is not reduced, they tend to avoid the situation by giving less efforts to deal with the stressful situation. As men are more socialized to use more active strategies involving instrumental coping it can act as a protective factor when dealing with stress. But inhibition of emotional responses in long run can lead to interpersonal problems, long term depression, anxiety which is difficult in identifying at earlier stages which can affect

Table 2. Mean, SD, t-value of different dimension of coping styles by gender.

\begin{tabular}{ccccccc}
\hline Coping Styles & \multicolumn{2}{c}{ Male } & \multicolumn{2}{c}{ Female } & t value & Level of Significance \\
\hline Rational & Mean & SD & Mean & SD & & \\
& 31.2 & 7.095 & 31.05 & 7.194 & $\mathrm{t}_{(98)}=0.10$ & Not significant \\
Detached & 25.4 & 6.106 & 21.6 & 6.014 & $\mathrm{t}_{(98)}=3.12$ & Significant at 0.01 level \\
Emotional & 19.11 & 6.799 & 22.163 & 7.76 & $\mathrm{t}_{(98)}=2.07$ & Significant at 0.05 level \\
Avoidance & 21.37 & 6.038 & 18.85 & 5.43 & $\mathrm{t}_{(98)}=2.20$ & Significant at 0.05 level \\
\hline
\end{tabular}


their physical and psychological health in later stages of life. It is also revealed that female young adults are significantly higher on emotional coping style than male counterpart. In the case of emotional coping styles females have a higher Mean and SD (22.16 and 7.16 respectively) than males with Mean 19.11 and SD 6.79. This finding is corroborated by the findings of Billings and Moos (1981) which reported that women made frequent use of emotion discharge coping than men. This finding implies that women tend to have more feelings and thoughts than their male counterparts and prefer to use social support from friends, family and significant others. Females generally uses emotion focused coping strategies while dealing with stress, on the other hand males uses problem focused or instrumental coping style, when handling stressful experiences which has been correlated by many studies (Endler \& Parker, 1994; Matud, 2004; Ptacek et al., 1994, Billings \& Moos, 1981; Folkman \& Lazarus, 1980). Various researches have reported that women when using emotional coping styles in a greater degree while managing stress there is an increased anxiety and depressive symptoms over time (Mezulis et al., 2002; Kelly et al., 2008; Matud, 2004; Kuehner, 2003), which is overall supporting the findings.

To determine the significant relationship between Positive Psychological Capital (hope, resilience, optimism and efficacy) and Coping styles (rational, detached, emotional and avoidance), product moment correlation of coefficient was computed and presented in Table 3.

Above findings indicate all four dimensions of positive PsyCap have significant and positive correlation with rational coping style and the reverse trend is visible in case of emotional coping style. Detached coping style is significantly and positively correlated with resilience and optimism. Finding implies that positive psychological capital leads to action based problem solving efficient coping strategies. Dispositional optimism makes less use of avoidance strategies such as denial and giving up (Carver et al., 1993). It may also be suggested that optimists have more positive health habits and generally more adaptive coping style. Resilience protects us from stress, decreases the anxiety symptoms resulting in positive adaptation in the face of significant adversity. Researchers have found that individuals who have high levels of resilience are protected from stress, with better living conditions and higher performance levels. Hope motivates to succeed at

Table 3. Correlation of coefficient between positive psychological capital (PsyCap) and coping styles.

\begin{tabular}{ccccc}
\hline $\begin{array}{c}\text { Positive Psychological } \\
\text { Capital (PsyCap) }\end{array}$ & $\begin{array}{c}\text { Rational Coping } \\
\text { Style }\end{array}$ & $\begin{array}{c}\text { Detached Coping } \\
\text { Style }\end{array}$ & $\begin{array}{c}\text { Emotional Coping } \\
\text { Style }\end{array}$ & $\begin{array}{c}\text { Avoidant Coping } \\
\text { Style }\end{array}$ \\
\hline Hope & $0.38^{* *}$ & 0.09 & $-0.32^{* *}$ & 0.04 \\
Self-Efficacy & $0.39^{* *}$ & 0.086 & $-0.44^{* *}$ & -0.18 \\
Resilience & $0.47^{* *}$ & $0.21^{*}$ & $-0.47^{* *}$ & -0.13 \\
Optimism & $0.44^{* *}$ & $0.23^{*}$ & $-0.48^{* *}$ & -0.12 \\
\hline
\end{tabular}

${ }^{*}$ Significant at the 0.01 level ( 2 tailed), ${ }^{*}$ Significant at the 0.05 level ( 2 tailed). 
a specific task, redirecting path towards goals leading to positive emotions which enhances rational adaptive coping style like facing the stressor and working to overcome it, done through accepting the reality, exposing oneself towards it, and understanding how to move forward, leading to optimal functioning and better health outcomes. Self-Efficacy which is a belief and confidence in oneself about one's capacities and abilities, exercising control over events that affect our lives and managing the demands of everyday life which helps to better face and handle stress by adapting more effective problem solving coping (rational), by being more proactive, engagement in one's problem, positive re-interpretation of the stressor and growth, and by managing the problem that causes stress.

All the dimensions of PsyCap have negative relationship with emotional coping style as emotional coping style is an ineffective coping strategy in long run like distortion of thinking, inappropriate self-evaluation, minimizing stress through negative ways, thought etc, which is not focusing on accepting personal challenges, positive emotions and appraisal, being confident and positive motivation to achieve goals which increases overall well-being of the individuals. PsyCap has a significant positive impact on the adaptive rational coping style by changing and modifying the fundamental causes of the stress, which is practical and developing active strategy to avoid the source of stress.

\section{Conclusion}

The present study determines different dimensions of PsyCap and coping styles among young adults. The study also shows the relationship between PsyCap and coping styles. The findings of the present research demonstrate that hope and resilience are higher among female young adults. In case of coping style, female young adults are significantly higher on emotional coping style whereas males are significantly higher on detached and avoidance. Significant and positive correlation exists between all dimensions of PsyCap and rational coping style whereas the reverse trend is visible in case of emotional coping style. Detached coping style is significantly and positively correlated with resilience and optimism.

\section{Limitations}

The limitations of the present study are as follows:

- Responses in the present study were based on the self-report. Future research should replicate findings using other methodologies (Example: interviews, observations).

- The findings may not be generalizable fully because the sample drawn for the study is based on one city (Kolkata), which apparently has less number of sample size, as compared to the whole young adult population.

- Study is cross-sectional in nature, thus preventing us to draw causal inferences from the results; longitudinal study may provide better insight, to see the long term effects of these factors (PsyCap and Coping Styles) on the Participants. 


\section{Implications}

In spite of having limitations, the result of the study has significant implication.

- The study implies to use psychological capital as a more valuable resource for students to help students persevere in their studies in psychologically \& physically healthier manner among young adults (e.g. in various jobs, college, personal life etc).

- It can also be suggested for the usage of more problem-solving coping strategies among females and less emotional inhibition among males, and providing the young adults with appropriate adaptive coping skills which may increase the ability to manage stress effectively.

- There is a need for the college administration to increase counselling services, to mitigate the level of stress among students. Appropriate coping skills may be taught to students so that they learn to avoid maladaptive coping strategies by inculcating adaptive coping strategies and enhancing the level of the Psychological capital.

- Training programs may be arranged to improve young adult's long-term health outcomes and to promote "positive" psychological outlook.

- University educators need to focus on the aspects of the positive psychological capital within the academic curriculum.

\section{Future Work}

- Future work may include professionals from different types of organization.

- Large number of sample may be considered in future for generalizing the findings.

- Studies can be conducted including people from different states of India to explore how positive psychological capital and coping style vary with respect to culture.

- Longitudinal study may be conducted in future to determine the cause and effect relationship.

\section{Conflicts of Interest}

The authors declare no conflicts of interest regarding the publication of this paper.

\section{References}

Al-Bahrani, M., Aldhafri, S., Alkharusi, H., Kazem, A., \& Alzubiadi, A. (2013). Age and Gender Differences in Coping Style across Various Problems: Omani Adolescent's Perspective. Journal of Adolescence, 36, 303-309. https://doi.org/10.1016/j.adolescence.2012.11.007

Avey, J. B., Hughes, L. W., Norman, S. M., \& Luthans, K. (2008). Using Positivity, Transformational Leadership and Empowerment to Combat Employee Negativity. Leadership and Organization Development Journal, 29, 110-126.

https://doi.org/10.1108/01437730810852470

Avey, J. B., Luthans, F., Smith, R. M., \& Palmer, N. F. (2010). Impact of Positive Psycho- 
logical Capital on Employee Well-Being over Time. Journal of Occupational Health Psychology, 15, 17-28. https://doi.org/10.1037/a0016998

Avey, J. B., Patera, J. L., \& West, B. J. (2006). The Implications of Positive Psychological Capital on Employee Absenteeism. Journal of Leadership \& Organizational Studies, 13, 42-60. https://doi.org/10.1177/10717919070130020401

Avey, J. B., Reichard, R. J., Luthans, F., \& Mhatre, K. H. (2011). Meta-Analysis of the Impact of Positive Psychological Capital on Employee Attitudes, Behaviors, and Performance. Human Resource Development Quarterly, 22, 127-152.

https://doi.org/10.1002/hrdq.20070

Baron, R. A., Franklin, R. J., \& Hmieleski, K. M. (2013). Why Entrepreneurs Often Experience Low, Not High, Levels of Stress. Journal of Management, 42, 742-768. https://doi.org/10.1177/0149206313495411

Billings, A. G., \& Moos, R. H. (1981). The Role of Coping Resources \& Social Resources in Attenuating the Stress of Live Events. Journal of Behavioural Medicine, 4, 139-157. https://doi.org/10.1007/BF00844267

Carver, C. S., Pozo, C., Harris, S. D., Noriega, V., \& Al, E. (1993). How Coping Mediates the Effect of Optimism on Distress: A Study of Women with Early Stage Breast Cancer. Journal of Personality and Social Psychology, 65, 375-390. https://doi.org/10.1037/0022-3514.65.2.375

Diener, E., \& Biswas-Diener, R. (2008). The Science of Optimal Happiness. Boston: Blackwell Publishing. https://doi.org/10.1002/9781444305159

Dunkley, D. M., Zuroff, D. C., \& Blankstein, K. R. (2003). Self-Critical Perfectionism and Daily Affect. Dispositional \& Situational Influences on Stress and Coping. Journal of Personality \& Social Psychology, 58, 844-854. https://doi.org/10.1037/0022-3514.84.1.234

Elklit, A. (1996). Coping Styles Questionnaire: A Contribution to the Validation of a Scale for Measuring Coping Strategies. Personality and Individual Differences, 21, 809-812. https://doi.org/10.1016/0191-8869(96)00123-7

Endler, N. S., \& Parker, J. D. (1994). Assessment of Multidimensional Coping: Task, Emotion, and Avoidance Strategies. Psychological Assessment, 6, 50-60. https://doi.org/10.1037/1040-3590.6.1.50

Fink, J. E. (2014). Flourishing: Exploring Predictors of Mental Health within the College Environment. Journal of American College Health, 62, 380-388. https://doi.org/10.1080/07448481.2014.917647

Folkman, S., \& Lazarus, R. S. (1980). An Analysis of Coping in a Middle Aged Community Sample. Journal of Health and Social Behaviour, 21, 219-239. https://doi.org/10.2307/2136617

Frydenberg, E. (1997). Adolescent Coping: Theoretical and Research Perspectives. Londonm, New York: Routledge.

Hampel, P., \& Petermann, F. (2005). Age and Gender Effects on Coping in Children and Adolescents. Journal of Youth and Adolescence, 34, 73-83. https://doi.org/10.1007/s10964-005-3207-9

Hiebert, B. (1983). A Framework for Planning Stress Control Interventions. Canadian Counsellor, 17, 51-61.

Hiebert, B. (2002). Relaxation in the Classroom: A Win-Win Life Skill. Guidance \& Counselling, 17, 73-81.

Kelly, M. M., Tyrka, A. R., Price, L. H., \& Carpenter, L. L. (2008). Sex Differences in the Use of Coping Strategies: Predictors of Anxiety and Depressive Symptoms. Depression 
and Anxiety, 25, 839-846. https://doi.org/10.1002/da.20341

Kuehner, C. (2003). Gender Differences in Unipolar Depression: An Update of Epidemiological Findings and Possible Explanations. Acta Psychiatrica Scandinavica, 108, 163-174. https://doi.org/10.1034/j.1600-0447.2003.00204.x

Larson, M., \& Luthans, F. (2006). Potential Added Value of Psychological Capital in Predicting Work Attitudes. Journal of Leadership \& Organizational Studies, 13, 75-92. https://doi.org/10.1177/10717919070130020601

Laschinger, H. K. S., \& Grau, A. L. (2012). The Influence of Personal Dispositional Factors and Organizational Resources on Workplace Violence, Burnout, and Health Outcomes in New Graduate Nurses: A Cross-Sectional Study. International Journal of Nursing Studies, 49, 282-291. https://doi.org/10.1016/j.ijnurstu.2011.09.004

Lawrence, J., Ashford, K., \& Dent, P. (2006). Gender Differences in Coping Strategies of Undergraduate Students and Their Impact on Self-Esteem and Attainment. Active Learning in Higher Education, 7, 273-281. https://doi.org/10.1177/1469787406069058

Lazarus, R. S. (2003). Does the Positive Psychological Movement Have Legs? Psychological Inquiry, 14, 93-109. https://doi.org/10.1207/S15327965PLI1402_02

Lazarus, R., \& Folkman, S. (1984). Stress, Appraisal, and Coping. New York: Springer.

Luthans, F. (2002). Positive Organizational Behavior: Developing and Managing Psychological Strengths. Academy of Management Perspectives, 16, 57-72.

https://doi.org/10.5465/ame.2002.6640181

Luthans, F., \& Youssef, C. M. (2004). Human, Social, and Now Positive Psychological Capital Management. Organizational Dynamics, 33, 143-160. https://doi.org/10.1016/j.orgdyn.2004.01.003

Luthans, F., \& Youssef, C. M. (2007b). Emerging Positive Organizational Behavior. Journal of Management, 33, 321-349. https://doi.org/10.1177/0149206307300814

Luthans, F., Avey, J. B., \& Patera, J. L. (2008). Experimental Analysis of a Web-Based Training Intervention to Develop Positive Psychological Capital. Academy of Management Learning \& Education, 7, 209-221.

https://doi.org/10.5465/amle.2008.32712618

Luthans, F., Avolio, B. J., Avey, J. B., \& Norman, S. M. (2007a). Positive Psychological Capital: Measurement and Relationship with Performance and Satisfaction. Personnel Psychology, 60, 541-572. https://doi.org/10.1111/j.1744-6570.2007.00083.x

Luthans, F., Youssef, C. M., \& Avolio, B. J. (2007c). Psychological Capital (pp. 237-238). New York: Oxford University Press. https://doi.org/10.1093/acprof:oso/9780195187526.001.0001

Matud, M. (2004). Gender Differences in Stress and Coping Styles. Personality and Individual Differences, 37, 1401-1415. https://doi.org/10.1016/j.paid.2004.01.010

Mezulis, A. H., Abramson, L. Y., \& Hyde, J. S. (2002). Domain Specificity of Gender Differences in Rumination. Journal of Cognitive Psychotherapy, 16, 421-434. https://doi.org/10.1891/jcop.16.4.421.52524

Newman, A., Ucbasaran, D., Zhu, F., \& Hirst, G. (2014). Psychological Capital: A Review and Synthesis. Journal of Organizational Behavior, 35, 120-138. https://doi.org/10.1002/job.1916

Ptacek, J. T., Smith, R. E., \& Dodge, K. L. (1994). Gender Differences in Coping with Stress: When Stressor and Appraisals Do Not Differ. Personality and Social Psychology Bulletin, 20, 421-430. https://doi.org/10.1177/0146167294204009

Riolli, L., Saviciki, V., \& Richards, J. (2012). Psychological Capital as a Buffer to Student Stress. Psychology, 3, 1202-1207. https://doi.org/10.4236/psych.2012.312A178 
Roddenberry, A., \& Renk, K. (2010). Locus of Control and Self-Efficacy: Potential Mediators of Stress, Illness, and Utilization of Health Services in College Students. Child Psychiatry \& Human Development, 41, 353-370.

https://doi.org/10.1007/s10578-010-0173-6

Roger, D., Jarvis, G., \& Najarian, B. (1993). Detachment and Coping: The Construction and Validation of a New Scale for Measuring Coping Strategies. Personality and Individual Differences, 15, 619-626. https://doi.org/10.1016/0191-8869(93)90003-L

Seligman, M. E., \& Csikszentmihalyi, M. (2000). Positive Psychology: An Introduction. American Psychologist, 55, 5-14. https://doi.org/10.1037/0003-066X.55.1.5

Weinstein, N., Brown, K. W., \& Ryan, R. M. (2009). A Multi-Method Examination of the Effects of Mindfulness on Stress Attribution, Coping and Emotional Well-Being. Journal of Research in Personality, 43, 374-385. https://doi.org/10.1016/j.jrp.2008.12.008

Yan, Q., \& Zhang, L. (2016). Research on Psychological Capital of College Graduates: The Mediating Effect of Coping Styles. In Proceedings of the 2016 4th International Conference on Management Science, Education Technology, Arts, Social Science and Economics (msetasse-16) (pp. 1643-1644). https://doi.org/10.2991/msetasse-16.2016.368 